\title{
Quando o privado tem interesse público: a fundação e a trajetória institucional da Faculdade Livre de Direito de Porto Alegre (1900-1937) ${ }^{1}$
}

Luiz Alberto GRIJÓ•

\begin{abstract}
Resumo: $O$ presente artigo enfoca a trajetória institucional da Faculdade de Direito de Porto Alegre desde a sua fundação em 1900 até 1937. Primeiro são analisados seus diretores, depois as relações entre a escola e as leis federais e, por fim, sua evolução patrimonial. Ao contrário do que alguns trabalhos sustentam, pode-se afirmar que sem o apoio das administrações públicas, notadamente pelos aportes de recursos financeiros e patrimoniais, teria sido inviável a criação e a manutenção da instituição. A existência da escola, inicialmente uma sociedade de direito privado, pois, esteve sempre atrelada ao apoio de lideranças político-partidárias da facção política hegemônica no estado brasileiro do Rio Grande do Sul.
\end{abstract}

Palavras-chave: Ensino jurídico no Rio Grande do Sul; Ensino jurídico no Brasil; Faculdade de Direito de Porto Alegre; Faculdades de Direito no Brasil; Formação jurídica e política.

A responsabilidade pela fundação da Faculdade Livre de Direito de Porto Alegre em 1900 é quase unanimemente atribuída pelas fontes a quatro "personagens" principais e a um grupo de servidores públicos em especial. São sempre

- Doutor em História Social pela Universidade Federal Fluminense (UFF). Professor do Departamento e do Programa de Pós-Graduação em História - Universidade Federal do Rio Grande do Sul - IFCH - UFRGS - Campus do Vale - 91509-900 - Porto Alegre - RS - Brasil. E-mail: lgrijo@uol.com.br 
destacados os nomes dos desembargadores do Superior Tribunal do Estado (STE) James de Oliveira Franco e Souza e Carlos Thompson Flores e dos líderes políticos do Partido Republicano Rio-Grandense (PRR), então dominante, Júlio de Castilhos, seu chefe, principal líder e ex-presidente do estado, e Borges de Medeiros, presidente do estado. É relevada também a importância dos magistrados em geral, sendo que Franco chega a apontar que "sem medo de errar, pode-se dizer que a Faculdade de Direito nasceu e tomou corpo no seio da mais alta corte de justiça do estado" (FRANCO, 1971; ver também SANTOS, 2000: 31-36). Quanto às participações de Castilhos e Borges, o último também desembargador, mas afastado para exercer a presidência do estado, são apontadas desde a "idéia" da fundação da Faculdade, que teria sido de Castilhos, o apoio "moral" de ambos, bem como o aporte material do governo estadual, que cedeu espaços em prédios públicos para a instalação da instituição.

Como foram os casos das demais escolas superiores instaladas no Rio Grande do Sul à mesma época (Faculdade de Medicina e Escola de Engenharia), a fundação da Faculdade de Direito não se tratou de um empreendimento estatal. Embora vários de seus "fundadores" fossem ou tivessem sido detentores de cargos públicos de caráter político-partidário e à época fossem vinculados mais ou menos estreitamente ao PRR, foi na qualidade de bacharéis em direito e de particulares que se reuniram e articularam a estruturação do curso jurídico portoalegrense.

Foi, portanto, um empreendimento formalmente privado, de acordo com o que pregava Júlio de Castilhos e na linha inaugurada, ao menos como possibilidade legal no Brasil, pela reforma Leôncio de Carvalho de 1879 e ratificada nas regulamentações republicanas que se seguiram quanto ao "ensino livre".

O desembargador-presidente do STE, James de Oliveira Franco e Souza, então presidindo igualmente as reuniões preparatórias para a fundação da Faculdade, referiu que, além do "interesse" do STE no "êxito do empreendimento", a Faculdade 
era de "vital importância para a mocidade rio-grandense", já que "desta casa de ensino deverão sair os futuros magistrados, advogados e homens públicos do Rio Grande do Sul" (apud, FRANCO, 1971). No mesmo sentido, Santos aponta que a partir da escola se "iria coordenar a formação de uma nova estrutura na tessitura social, a de dar formação jurídica à mocidade conformada aos princípios republicanos". Por outro lado, no órgão de imprensa de propriedade do PRR, A Federação, a fundação da Faculdade recebeu em várias ocasiões destaque em sua primeira coluna, como na que saudou com uma profusão de adjetivos laudatórios a instalação festiva da escola publicada na edição de 4 de abril de 1900 (ver SANTOS, 2000: 32).

Ou seja, embora um empreendimento privado, a escola contou desde o princípio com o apoio do governo do estado e do chefe do PRR. Este ponto deve ser devidamente frisado porque um outro trabalho (MENDES, 1999) afirma que a fundação das escolas superiores no Rio Grande do Sul teria sido contrária aos interesses do governo estadual, embora as evidências apontem justamente no sentido contrário. Os argumentos levantados partem da noção de que as escolas superiores permitiriam a "formação de uma elite concorrencial, ou seja, diplomada academicamente e apta a questionar o poder político" do PRR. Segundo este ponto de vista, haveria uma disputa entre a "elite de bacharéis" e os "interesses da liderança política unipessoal" de Júlio de Castilhos. Assim, "institucionalizar o ensino superior no estado seria contraditório ao sistema político orientado pela monopolização do poder facilitada pelo acesso restritivo a faculdades do centro do país e pela dedicação exclusiva dos bacharéis a serviço do Estado". A fundação da Faculdade de Direito teria tido como resultado a "organização categorial dos bacharéis" (MENDES, 1999: 108-9).

Se, posteriormente, certos focos de críticas e mesmo oposição ao governo surgiram entre alunos e alguns professores das escolas superiores e, ao menos formalmente, o governo do $P R R$ e o partido em si procuravam mostrar-se alheios à organização destas instituições, seguindo suas diretrizes programáticas e os dispositivos constitucionais, isto não quer 
dizer que suas lideranças fossem contrárias ao ensino superior por este potencialmente viabilizar a formação de oposicionistas cultural e escolarmente habilitados.

Neste sentido, há um artigo publicado em $A$ Federação em fevereiro de 1904 que é esclarecedor. Embora seja um texto assinado por Oscar Ramos, quer dizer, não se trata de uma "opinião" da redação do jornal, o fato de ser publicado no órgão de imprensa do PRR é sintomático de uma posição que deveria ter algum respaldo no comando partidário. Segundo este, o Rio Grande do Sul sempre teria sido visto pelo resto do Brasil como "menor" intelectualmente, sendo a isto fadado até por causa de seu "clima". Mas a situação estaria mudando, pois "as três academias, direito, engenharia e medicina, vão impondo-se à consideração dos espíritos equânimes, que amam a instrução, porque dela depende a felicidade de um povo e a garantia de um regime" (RAMOS, 1904: 1). Mais ou menos oficialmente, pois, havia a noção clara de que a instrução superior era uma necessidade, até mesmo como garantia de sustentação para o próprio "regime republicano".

Retomando as palavras de James Franco e Souza acima citadas, é interessante notar que aqueles que o presidente do STE arrola como os objetivos da instituição que estava sendo estruturada, "formar magistrados, advogados e homens públicos do Rio Grande do Sul" podem ser comparados com os objetivos anteriormente propostos para a própria fundação dos cursos jurídicos no Brasil pouco mais de setenta anos antes. Novamente aparece a preocupação de fornecer quadros ao Estado, seja na magistratura, seja nos demais poderes. Os cursos deveriam formar genéricos "homens públicos" (ver GRIJÓ, 2005: 25 e seguintes).

Assim, é mais correto afirmar que presença das escolas superiores no Rio Grande do Sul permitia ao comando do PRR e do governo um controle sobre a formação superior não necessariamente por mecanismos administrativo-financeiros direitos, como seria no caso de um ensino superior "oficial", mas por meios mais difusos e informais que não eram menos eficazes, tais como a dependência destas de financiamentos e 
outras benesses dos poderes públicos, bem como através do exercício da patronagem e do uso de vínculos políticopartidários e de parentesco entre agentes das instituições e agentes do governo e/ou do partido. Muitas vezes a mesma pessoa tinha vinculações estreitas em todas estas instâncias.

Por outro lado, o trecho acima citado, que se refere a que se pretendia com a Faculdade de Direito dar uma "formação jurídica à mocidade conformada aos princípios republicanos", aponta para que um dos objetivos de sua fundação era o de formar e capacitar escolar e culturalmente uma elite dentre aqueles que já seriam de antemão "republicanos", ou seja, partidários ou simpatizantes do PRR. Sob este ponto de vista a Faculdade deveria ser uma espécie de escola de formação jurídica para jovens companheiros de partido, uma vez que a referência não diz respeito a formar republicanos, mas sim a dar formação jurídica aos que já o eram. Este é um outro elemento da relação entre a Faculdade e a política partidária que pode ser traduzido em termos da relação entre a Faculdade e o PRR, a primeira legitimando social, cultural e escolarmente o "republicanismo" associado aos membros ou proto-membros do segundo.

A fim de desenvolver este análise que enfoca os aspectos mais formais e propriamente institucionais, os seguintes pontos passam a ser destacados, todos tendo em vista as relações entre a Faculdade e a política partidária. Primeiro, os diretores que estiveram à frente da instituição durante o período em foco (1900-1937). Segundo, a trajetória da Faculdade em relação com as leis federais sobre o ensino e sua passagem de instituição privada à instituição pública estadual incorporada a uma estrutura universitária. Terceiro, buscou-se avaliar as condições materiais e patrimoniais da escola e sua dependência de recursos públicos. 


\section{Os Diretores}

Desde a sua fundação até 1937 a Faculdade de Direito porto-alegrense teve apenas três diretores. $O$ primeiro foi 0 desembargador Carlos Thompson Flores, que se manteve no cargo até 1904. O segundo foi o também desembargador Manoel André da Rocha, que permaneceria na direção da escola até 1935, quando foi sucedido pelo professor Luiz de Mello Guimarães, outro desembargador.

Como já salientado, Thompson Flores fora um dos principais articuladores da fundação da escola. Nascido na capital do estado, no período republicano fora constituinte estadual e membro da Assembléia dos Representantes (18911896) pelo PRR, tendo ingressado no STE em 1893, do qual foi vice-presidente em 1896 e 1897. Ocupou também o cargo de procurador geral do estado (1894-1904), função de importância estratégica e de estrita confiança dos chefes do governo, Júlio de Castilhos, até 1898, e depois Borges de Medeiros. Morreu em 1904 no exercício da direção da Faculdade, sendo que nela também lecionava a disciplina de Direito Privado.

Thompson Flores foi sucedido pelo professor Manoel André da Rocha, desembargador desde 1903 e presidente do STE de 1921 a 1935. Ele permaneceria no cargo de 1904 até 1935, quando se tornaria o primeiro reitor da recém-fundada Universidade de Porto Alegre (UPA). Pelo que se pôde verificar, há poucos dados biográficos mais detalhados sobre André da Rocha que tenham sido publicados ou que estejam à disposição do público, mas há algumas indicações que apontam para uma estreita relação entre ele e o presidente do estado Borges de Medeiros.

André da Rocha nasceu em Natal, Rio Grande do Norte, e fez seu curso de direito em Recife, formando-se em 1883. Foi para o Rio Grande do Sul ainda no período imperial (1885), assumindo juizados em comarcas do interior. No período republicano os indícios apontam que prestou apoio ao governo de Júlio de Castilhos. Em 1892, quando Castilhos é deposto, 
André da Rocha é afastado da magistratura e passa a advogar em Lagoa Vermelha, retomando a atividade de magistrado com a volta do PRR ao governo. Em 1896 se torna juiz em Porto Alegre, quando passa a ser convocado interinamente para compor o STE. Assume o cargo de desembargador efetivo em 1903, justamente na vaga aberta com o afastamento formal de Borges de Medeiros, o qual já não mais se encontrava de fato em exercício dessa função desde que assumira a presidência do estado pela primeira vez em 1898.

Suas ligações com Borges podem ser inferidas também pelo fato de que foi justamente no período inaugurado com a morte de Castilhos, no qual Borges estava tentando impor-se como líder do PRR, que André da Rocha foi nomeado chefe de polícia interino do estado (1904) e, no ano seguinte, se tornou o seu procurador geral. Pode parecer estranho, se é considerada a importância dos cargos que André da Rocha exercia, mas na correspondência passiva de Borges de Medeiros, enviada desde o município de Porto Alegre sob a guarda do Arquivo Borges de Medeiros (ABM) do Instituto Histórico e Geográfico do Rio Grande do Sul (IHGRS), há pouquíssimo material recebido pelo presidente enviado por Rocha. Isto, porém, pode indicar que as entrevistas pessoais entre ambos eram constantes, sendo, portanto, desnecessário a André da Rocha se dirigir freqüentemente ao seu "bom amigo e preclaro chefe" (ROCHA a MEDEIROS, 1905) por meio de correspondência escrita.

Foi encontrada uma única carta que deixa transparecer o caráter da relação em termos de troca de favores. André da Rocha escreve a Borges pedindo "encarecidamente que não se esqueça da promessa que me fez de que indicaria o nome de João [ilegível] de Oliveira Mendes" para uma promoção. Salientando que tinha conhecimento de vagas abertas, "tomo a liberdade (do que peço desculpas) de relembrar aquela promessa que significa um ato de justiça". André da Rocha ainda descreve as qualidades do seu apadrinhado e termina frisando que "o Marcos e o [ilegível] estão de acordo com a promoção" (ROCHA a MEDEIROS, 1913). "Marcos" é provavelmente o 
coronel Marcos de Andrade, um dos chefes mais importantes, senão o mais, do PRR no município de Porto Alegre.

André da Rocha, pois, era para o presidente do estado um apoio bastante conveniente naquele período crucial no qual estava em jogo a afirmação de sua liderança, a qual vinha sendo contestada por outros líderes importantes do PRR, o que levaria a dissidências no partido e à disputa eleitoral de 1907. Apadrinhando a "carreira" do magistrado oriundo de um estado longínquo da federação, Borges assegurava alguém em postos importantes que lhe devia pessoalmente gratidão e em quem podia confiar com maior segurança do que a que poderia dispensar em relação aos "coronéis" do PRR e outros de seus membros cujas relações com o partido eram antigas e baseadas em redes de relações pessoais há muito costuradas. Isto porque muitos deles se vinculavam à liderança de Júlio de Castilhos e não à de Borges e as suas relações de solidariedades pessoais estavam distribuídas entre os principais líderes partidários, dentre os quais Borges era apenas mais um, embora provavelmente o mais importante ainda antes da morte de Castilhos. Daí a conveniência para aquele que tentava impor-se como o novo "chefe unipessoal" do PRR de confiar a alguém de fora do Rio Grande do Sul postos centrais na estrutura burocrática do estado.

Em termos mais formais, em 1905 Borges de Medeiros solicitou à Congregação da Faculdade de Direito que examinasse e emitisse um parecer sobre o projeto do Código do Processo Civil e Comercial do Rio Grande do Sul. André da Rocha presidiu a comissão de professores composta ainda por Plínio Alvim, Joaquim Antônio Ribeiro, Timótheo Pereira da Rosa, Pedro Affonso Mibielli e Leonardo Macedônia Franco e Souza, tendo sido escolhido este último o relator geral. Dois anos depois a comissão enviou o trabalho ao governo do estado que o acatou e promulgou como o Código referido (ver VÁRIOS, 1927: 108-10).

Por fim, quando André da Rocha assume a reitoria da Universidade de Porto Alegre, a direção da Faculdade passa para o desembargador Luiz de Mello Guimarães. Nascido na 
cidade de Rio Grande, formou-se em São Paulo em 1897 e vinculou-se à Faculdade de Porto Alegre em 1923, depois de ter sido catedrático da Faculdade de Direito de Pelotas. Desde formado seguiu carreira na magistratura, tendo assumido diversas comarcas no interior. Tornou-se desembargador em 1920, quando se transfere de Pelotas para Porto Alegre. Em 1932 foi eleito vice-presidente do STE e designado presidente do Tribunal Regional Eleitoral (TRE). Em 1935 assume a presidência da Corte de Apelação do Estado, nova nomenclatura do antigo STE. Aposentou-se na magistratura no ano seguinte.

Mello Guimarães não ocupou cargos eletivos e não consta ter sido filiado a partidos políticos. Porém, não atuou somente na magistratura. Suas relações com o PRR e, após 1930, com o interventor e depois governador eleito Flores da Cunha, parecem ter sido estreitas. Entre 1923 e 1928 assumiu por diversas vezes o cargo de procurador geral do estado, o que indica uma relação de proximidade com Borges de Medeiros. Em 1931 e 1932 novamente é indicado procurador geral e também integra uma comissão revisora do Código de Processo Civil e Comercial do estado. Colaboraria também na comissão que elaborou um anteprojeto de Constituição estadual em 1934 e no ano seguinte foi designado por Flores da Cunha para elaborar um ante-projeto de reorganização judiciária do Rio Grande do Sul.

Os três primeiros diretores da Faculdade, pois, tinham em comum o fato de serem primordialmente magistrados, todos já na condição de desembargadores, bem como possuírem vínculos importantes com a instituição. Thompson Flores e André da Rocha foram dois dos organizadores da Faculdade, Mello Guimarães fora lente desde 1923 até assumir a direção em 1935. Por outro lado, os vínculos que possuíam com a política partidária, ou ao menos com os chefes do governo estadual até 1937, podem ser percebidos de forma direta. Todos os três foram procuradores gerais do estado e chegaram a desembargadores sob governos do PRR. Por outro lado, Thompson Flores ocupou cargos eletivos pelo partido e André da Rocha foi chefe de polícia do estado. 
Tais relações estreitas também podem ser inferidas se são considerados o caráter da magistratura e as formas de ingresso nela. Trata-se em princípio de uma carreira técnico-jurídica supostamente paralela e autônoma frente à política partidária. Porém, João Neves da Fontoura refere que, até 1915, no Rio Grande do Sul a magistratura "compunha-se em sua grande maioria de nortistas ou nordestinos". Somente em 1904 formouse a primeira turma da Faculdade de Direito de Porto Alegre e, até então, a oportunidade de estudar direito era reservada aos rio-grandenses "que dispunham de alguns bens de fortuna" para o fazerem no Rio de Janeiro, São Paulo ou Recife. Ao retornarem para o Rio Grande do Sul, porém, não se inclinavam para "cargos públicos" por serem estes "mal remunerados, mas para a advocacia e a política". Já os "nortistas ou nordestinos" que se propunham a migrar para o Rio Grande do Sul e ocupar tais cargos deveriam lançar mão de alguns expedientes. $O$ "pretendente recorria ao governador do seu estado, e este o recomendava a Pinheiro Machado, aqui no Rio, de onde o jovem interessado seguia para o Sul, com carta de apresentação, lá encontrando todas as facilidades" (FONTOURA, 1969: 90).

Franco, comentando as reformas judiciais de Júlio de Castilhos a partir de conclusões retiradas das declarações do próprio sobre a promulgação do Código de Organização Judiciária de 1895 - lei que contemplava critérios de ingresso na magistratura por concurso público e de ascensão na carreira, principalmente acesso ao STE, por antiguidade, contemplava ainda a vitaliciedade e inamovibilidade dos magistrados em seus cargos (ver GOVERNO do estado do Rio Grande do Sul, 1920) -, refere que o então chefe do PRR teria procurado "cercar de garantias a magistratura, fazendo questão cerrada de assegurar-lhe a independência ante o Poder Executivo estadual, num grau talvez maior que a dos dias atuais" (FRANCO, 1988: 155). Isto contrasta frontalmente com o que relata João Neves que, ao contrário, aponta qual o caminho "regular" para a ocupação destes cargos, ou seja, eles eram políticopartidarizados enquanto objeto de patronagem. 
Deste modo, o devidamente credenciado recém chegado aspirante a magistrado encontrava uma posição que devia aos favores obtidos a partir deste segmento de rede que se iniciava em seu estado natal, envolvia Pinheiro Machado, Borges de Medeiros e desembargadores do STE. Só assim lograva sua nomeação para o cargo almejado, normalmente, de início, um juizado em alguma comarca do interior. As possibilidades de que este novo juiz viesse a tornar-se um cliente do próprio Borges ou ao menos um "simpatizante" do partido político dominante eram enormes, sob pena mesmo de cair em desgraça e ter sua carreira truncada pela falta de promoções e/ou por transferências para comarcas mais obscuras. Poderiam, igualmente, cair na teia clientelística do chefe partidário do município ao qual fora designado.

Ou seja, o pleiteante, provido de um capital de relações sociais em sua terra natal e do título de bacharel, acionava algum político conterrâneo que, por seu turno, acionava o então nacionalmente muito bem situado senador rio-grandense Pinheiro Machado. Este usava suas relações com Borges ou com outros partidários e/ou desembargadores para indicar o nome do candidato. Este último aportava no Rio Grande do Sul com um emprego garantido, "encontrando todas as facilidades", nas palavras de João Neves. A indicação era já o ato de nomeação, mas que vinha acompanhada de uma dívida para com os mediadores acionados. É claro que era esperada do beneficiário a fidelidade para com seus padrinhos, ou, por outra, a disposição de prestar favores de acordo com o princípio da reciprocidade quando fossem estes solicitados. O novo magistrado iniciava suas atividades já inserido em redes de relações que, no caso da política regional, tinham ao centro a figura do presidente do estado.

E se este era o caso para os imigrados do Norte do país, o caso de rio-grandenses não era diferente, sendo apenas outros os mediadores acionados para a ocupação dos cargos, além do próprio Pinheiro. Ou seja, o que regrava o acesso aos cargos da magistratura e às promoções não eram principal e precipuamente critérios meritocráticos objetivos de competência 
técnica e profissional, os concursos públicos ou a antiguidade que estavam formalmente contemplados na Constituição de 1891 do estado e no Código de 1895, conforme sustenta Franco, mas o jogo das relações de patronagem e clientela.

Como apontado, durante todo o período no qual a Faculdade foi uma instituição de direito privado, teve apenas dois diretores, sendo que um deles se manteve no cargo durante 31 dos 34 anos de tal regime jurídico. Como se tratava de André da Rocha, se pode inferir que o governo do estado atribuía grande importância à instituição, a qual deveria contar à sua frente com alguém de estreitas relações com o líder do PRR. Por outro lado, o fato de que a direção era uma função exercida a partir da escolha pelos membros da Congregação da Faculdade, ou seja, o diretor era eleito pelo voto dos próprios professores, pode indicar tanto uma inclinação da maioria do corpo docente a apoiar o governo, quanto também um modo conveniente à instituição em si para continuar recebendo benesses deste ao manter no seu cargo mais importante alguém da confiança do presidente do estado. Com a estadualização em 1934, a ingerência do chefe do governo na escola passaria a ser ainda mais intensa, pois agora a dependência administrava passava a ser direta, bem como a nomeação de pessoal passava a ser de competência do governo estadual.

\section{As reformas federais no ensino e a Faculdade de Direito}

Logo após a fundação da Faculdade, a Congregação empenhou-se em adequar seus estatutos, patrimônio e procedimentos ao que exigiam as leis federais a fim de buscar a equiparação às escolas oficiais. O modelo para os ajustes estatutários foi o da Faculdade Livre de Direito do Rio de Janeiro. Assim, entre 1900 e 1903 o governo do estado e os parlamentares federais do PRR foram acionados para atuarem junto ao governo central. Em 6 de julho de 1903 um decreto federal reconhecia a equiparação, um ano antes que se formasse 
a primeira turma de estudantes. A Congregação da Faculdade nomeou uma comissão de professores para agradecer, em visitas, os empenhos do presidente o estado, Borges de Medeiros, e do chefe do PRR, Júlio de Castilhos. A Federação publicou diversos artigos saudando o fato (ver TILL, 2000: 109-15 e FRANCO, 1971).

No primeiro aniversário do decreto de equiparação, novamente $\mathrm{o}$ jornal do $\mathrm{PRR}$ dá destaque às respectivas comemorações. Em 6 e 7 de julho de 1904, A Federação noticiava e descrevia a "marche aux flambeaux", seguida de discursos de professores e estudantes os quais explicitavam os agradecimentos a Júlio de Castilhos, falecido em outubro do ano anterior, Borges de Medeiros, ao presidente Rodrigues Alves e ao ministro do Interior, José Joaquim Seabra.

Nos marcos cronológicos aqui em foco, a questão do reconhecimento federal e da conseqüente inspeção pela União da Faculdade ainda teria desdobramentos. Até 1911, manteve-se a situação inaugurada em 1903. Ao final deste período, um riograndense que ocupava o ministério da Justiça e Interior do governo Hermes da Fonseca elaboraria o decreto número 8659, logo posto em vigor, que, na esteira de leis anteriores desde o período imperial, novamente reformava o ensino no Brasil. Tratase da chamada reforma Rivadávia Corrêa, considerada como o coroamento das legislações sobre a educação no Brasil que tiveram como norte a questão da liberdade de ensino (CORRÊAA, 1911).

Antes de enfocar esta reforma, porém, há que se levar em conta a situação do ensino superior no Brasil nos inícios do regime republicano. Em termos mais gerais com respeito à educação, "a República é proclamada sem um programa prospectivo definido, embora o ideal federativo [...] traduzisse as esperanças dos liberais radicais [...], assim como as propostas de liberdade de ensino traduziam o ideal educacional" (BASTOS, 2000: 153). As leis e decretos republicanos viriam ao encontro de noções então correntes em parte da elite política nacional quanto a que o ensino deveria ser leigo e que deveria prevalecer a liberdade de ensino (ver GRIJÓ, 2005: 90 e seguintes). O 
decreto de 2 de janeiro de 1891, conhecido como reforma Benjamin Constant, então ministro da Instrução Pública, dispunha que o ensino poderia ser de competência federal, estadual e particular, consagrando a questão da liberdade de ensino em moldes semelhantes aos inaugurados com a reforma Leôncio de Carvalho ainda do período imperial, quer dizer, a liberdade de ensino como fundamentalmente a liberdade de particulares ensinarem nas escolas oficiais e/ou criarem "cursos livres" (BASTOS, 2000: 156). Nesta linha se organizaram as faculdades livres espalhadas por alguns estados da federação, como as que se instalaram no Rio Grande do Sul, à época.

Com respeito aos currículos e organização dos cursos de direito, a reforma de 1891 dividia os cursos de Recife e São Paulo em três: ciências jurídicas, ciências sociais e notariado, sendo que o primeiro habilitaria para a advocacia e magistratura, o segundo habilitaria para cargos diplomáticos e direção de órgãos públicos e o terceiro habilitaria para ofícios de justiça. $O$ grau de doutor seria concedido aos que fossem bacharéis nos cursos de ciências jurídicas e sociais e defendessem tese (BASTOS, 2000: 154-5). Era abolido dos currículos o direito eclesiástico, uma vez que o novo Estado se apresentava como laico, e era dada ênfase maior à filosofia e história do direito do que ao direito natural. Segundo Bastos, porém, as reformas curriculares republicanas não foram, como antes teria ocorrido à época da fundação dos cursos jurídicos na década de 1820, reflexo de debates parlamentares e muito menos fruto de "discussões pedagógicas profundas". Não traduziram "qualquer proposta de compreensão do fenômeno jurídico" e não representaram uma "ruptura com os fundamentos do ensino jurídico do Império". O que ocorreu foi uma espécie de ajuste que afastava as influências dos direitos eclesiástico e natural, assim como do direito romano, e dava maior ênfase à história do direito, inclusive do direito nacional, e à filosofia do direito. Procurou-se apenas secularizar o ensino jurídico (BASTOS, 2000: 155-6) e retirar dele conteúdos suspeitos de terem servido à legitimação do regime monárquico. 
Em 1895, novo diploma legal vinha reorganizar o ensino jurídico no país. Os cursos de notariado e de ciências sociais foram abolidos, restando o bacharelado em ciências jurídicas e sociais, agora num curso de cinco anos. Curricularmente, algumas cadeiras foram criadas, mas, no geral, mantiveram-se "as mesmas linhas e tendências de orientação" anteriores (BASTOS, 2000: 157).

A lei de 1895 também buscou regular a instalação dos cursos jurídicos nas faculdades livres que se iam criando no país, bem como "corrigir a prática abusiva da freqüência livre, transmudada em ausência de freqüência" (BASTOS, 2000: 158). Assim, a lei previa que as faculdades livres que se propusessem a obter o reconhecimento federal deveriam ter um patrimônio mínimo de 50:000\$000, uma freqüência mínima de 30 alunos em dois anos, estatutos concordes com a lei e contar com um fiscal federal. Estava prevista também a suspensão das atividades da escola, por um ou dois anos, que não observasse as regras de admissão à matrícula e de realização de exames (BASTOS, 2000: 158). Quanto à freqüência, a lei a tornava obrigatória. Porém, não tardaram recursos e novos projetos de lei apreciados no Congresso que levaram ao relaxamento da obrigatoriedade de freqüência.

Nos marcos da vigência da lei de 1895 e dos ajustes operados por uma lei de 1901 é que foi criada e logrou a equiparação com as escolas oficiais a Faculdade de Direito de Porto Alegre. Contudo, como já apontado, a lei que traria conseqüências mais significativas para a instituição, revelando inclusive sua estreita relação com o governo estadual, foi a de 1911.

O ministro da Justiça e Interior Rivadávia da Cunha Corrêa era membro do PRR. Foi alçado ao cargo com a posse na presidência da República de Hermes da Fonseca (1910-1914), justamente o momento que Love identificou como sendo o da "ascensão do Rio Grande do Sul na política nacional" (LOVE, 1975: 146 e seguintes). Passado o conturbado período da guerra civil (1893-5) e o da crise sucessória dentro do próprio PRR, ocorrida com a morte de Júlio de Castilhos e que terminou com a 
consolidação da liderança de Borges de Medeiros (1907), o Rio Grande do Sul passou a representar uma força político-partidária nacional não negligenciável.

O crescimento populacional e econômico se refletiam em mais recursos materiais para o governo do estado, bem como num maior número de eleitores mobilizáveis. Por outro lado, como já apontado, o Rio Grande do Sul contava entre seus parlamentares federais com o senador Pinheiro Machado, um dos articuladores principais da candidatura Hermes da Fonseca, bem como com uma bancada razoavelmente disciplinada no sentido de seguir as decisões e orientações do presidente do estado e do próprio Pinheiro, pois que quase exclusivamente composta por membros do PRR. Este foi o período no qual a ascendência de Pinheiro Machado atingiu seu ápice na política nacional.

Sem entrar em maiores detalhes a este respeito (ver LOVE, 1975: 145-75), basta para a questão do ensino aqui em pauta salientar que Rivadávia Corrêa era oriundo da região da fronteira oeste, justamente a zona de influência direta de Pinheiro e seu grupo familiar, lá possuíam terras de criação de gado, no Rio Grande do Sul. Além disso, no programa do Partido Republicano Conservador (PRC), criado no Congresso por Pinheiro como base de apoio ao governo Hermes da Fonseca, havia a previsão de sustentação do princípio da "liberdade de ensino", que seria uma "peculiar medida positivista de negar ao governo qualquer controle sobre o ensino superior", como uma das formas de "satisfazer os gaúchos" (LOVE, 1975: 160).

A reforma Rivadávia Corrêa, pois, se encaixa neste contexto tanto como conseqüência das linhas reformistas iniciadas na década de 1870 (reforma Leôncio de Carvalho), passando pelas leis republicanas, como o produto de um arranjo político que vinha ao encontro das teses programáticas, algumas transformadas em dispositivos constitucionais estaduais, há muito apregoadas pelo PRR, principalmente pelo seu então já falecido líder Júlio de Castilhos. A própria bancada do partido no Congresso apresentara uma emenda ao projeto de orçamento do 
ministério do Interior em 1910 que já propunha a linha depois seguida pela lei de 1911 (ver CUNHA, 1980: 162).

A reforma tinha como norte a chamada desoficialização do ensino. Assim, os estabelecimentos mantidos pelo governo central não teriam mais os privilégios que até então gozavam quanto aos títulos que distribuíam. Sejam os do colégio Pedro II, cujos ex-alunos podiam ingressar automaticamente nos cursos das escolas superiores, sejam os títulos expedidos por estas últimas, garantidores de exclusividades profissionais e de certos empregos públicos. Estas escolas passariam a ser autônomas frente ao governo central justamente no que diz respeito ao seu sustento financeiro e à sua organização disciplinar, pedagógica e administrativa. $O$ ingresso nos cursos superiores seria agora feito por meio da aprovação em um exame de admissão. Por outro lado, a lei extinguia completamente a fiscalização federal dos estabelecimentos de ensino estaduais e particulares e seus currículos passariam a ser organizados, de acordo com suas próprias conveniências, pelos respectivos corpos docentes, sem ser necessário seguir o modelo das escolas oficiais. A lei criou ainda um Conselho Superior de Ensino, que seria responsável pela gestão do processo de autonomia das instituições federais, e admitiu o exercício da livre-docência nas escolas superiores (ver CUNHA, 1980: 162-3 e CORRÊA, 1911).

Na Faculdade de Direito de Porto Alegre, já em 20 de abril de 1911, se reunia a Congregação e deliberava pelo imediato acatamento da lei de reforma, o que significou pôr-se desde então independente da fiscalização federal, pelo que o respectivo fiscal da Faculdade, um de seus fundadores e desembargador presidente do STE James de Oliveira Franco e Souza deixava o cargo. Por outro lado, foram abolidas as cadeiras de Filosofia do Direito, Direito Romano e Legislação Comparada. A primeira foi substituída pela cadeira de Enciclopédia Jurídica ou Teoria Geral do Estado e os conteúdos de direito romano seriam ministrados na cadeira de Direito Civil.

$\mathrm{Na}$ rapidez com que a Faculdade aderiu à lei Rivadávia Corrêa se percebe a estreita vinculação entre seu diretor e a maior parte dos seus professores com o presidente do estado e o 
PRR. Nos anos seguintes isto se evidenciaria ainda mais, quando um novo decreto de reforma seria promulgado pelo governo federal. Em 1915, a chamada reforma Carlos Maximiliano punha fim à referida linha de liberalização e/ou desoficialização do ensino no Brasil. A sua validade legal, porém, seria contestada pelo governo do estado do Rio Grande do Sul e a adequação da Faculdade à mesma seria recusada pela sua Congregação até 1917.

O governo Hermes terminara e Pinheiro Machado sofrera sérios abalos em sua ascendência no Congresso. Carlos Maximiliano era também rio-grandense de nascimento. Foi deputado federal eleito pelo PRR de 1909 até 1914 e de 1918 a 1923. Com a ascensão à presidência de Venceslau Brás, é escolhido ministro da Justiça e Negócios Interiores, mesmo contra a vontade de Pinheiro Machado que, não obstante, teria sido quem antes o indicara para seu primeiro mandato como parlamentar federal (segundo ABREU, 2001: 3647).

Em 1911 Maximiliano apoiara a reforma Rivadávia Corrêa junto com a bancada federal do PRR (ver MOACYR, 1942: 58-61). Em 1915, porém, passa a fazer coro às contestações que ela recebia no Congresso e fora dele. A tônica principal das críticas era o ataque à liberdade profissional, à proliferação de faculdades particulares que apenas "vendiam" diplomas, à possibilidade de autonomia financeira efetiva das faculdades públicas, que continuavam a depender do sustento federal, à incongruência do desprestigiamento dos diplomas superiores, uma vez que a exigência deles se mantinha para vários dos cargos públicos federais (CUNHA, 1980: 167 e VENÂNCIO FILHO, 1982: 208-13).

$\mathrm{Na}$ Exposição de Motivos do decreto de sua reforma, Maximiliano salienta que era "esplêndida a adiantada idéia da desoficialização do ensino". Porém, argumenta que no caso de sua aplicação no Brasil os resultados não foram bons porque, "em resumo, alguns lentes enriquecem, enquanto um aspecto de miséria e de abandono surpreende e entristece os que visitam os institutos" federais, pois os recursos auferidos pelas taxas cobradas não eram aplicados em benfeitorias para as 
instituições, mas apropriados pelos lentes das faculdades que optavam por aumentar seus vencimentos. "O ideal colimado pelo decreto [...] de 5 de abril de 1911 demora a distância formidável, acessível somente em 200 anos". Por outro lado, quanto às faculdades livres, Carlos Maximiliano critica a proliferação das mesmas e a "venda disfarçada de títulos" que muitas encobriam, perguntando ainda "para que cinco academias de direito na capital de um país de analfabetos"? (MAXIMILIANO, 1915).

Assim, a reforma de 1915 reintroduzia a fiscalização da União das faculdades livres e punha limites à existência daquelas possíveis de requererem equiparação aos cursos mantidos pelas escolas federais, novamente tomadas como modelos de organização administrativa, pedagógica e curricular. Manteve-se o exame de admissão, com o nome modificado para vestibular, e a livre-docência. Conservava o Conselho Superior de Ensino, agora como o órgão máximo de fiscalização dos estabelecimentos e para o qual as escolas equiparadas deveriam recolher uma "taxa de fiscalização". Uma vez reconhecidos como equiparados, os institutos não federais poderiam postular a validade de seus diplomas "junto ao Supremo Tribunal Federal, à Diretoria de Saúde Pública ou ao Ministério da Viação", órgãos estatais que "controlavam ou onde se exerciam atividades 'próprias' de advogados, médicos (dentistas, farmacêuticos e obstetras) e engenheiros". Não poderia haver cursos equiparados em cidades com menos de 100 mil habitantes, a menos que fosse capital de um estado com mais de um milhão de habitantes, bem como somente poderia haver até duas escolas de medicina, direito ou engenharia por estado em tais condições. Nos lugares onde houvesse uma escola oficial, somente uma outra particular poderia pleitear reconhecimento federal (CUNHA, 1980: 168-9).

A reforma Carlos Maximiliano, pois, interrompia a tendência anterior de desoficialização do ensino no Brasil e vinha no sentido de mais uma vez privilegiar, ao menos como parâmetro, o ensino oficial, bem como concentrar na União a ação reguladora nesta área.

Contra estas medidas, inicialmente, se posicionaram a direção e a Congregação da Faculdade de Direito de Porto 
Alegre. Segundo um ex-professor, à época bacharelando, Armando Dias de Azevedo, a situação seria modificada a partir da ação da maioria dos estudantes da escola: entre "os quase 100 acadêmicos de direito", havia "apenas dois dissidentes" (AZEVEDO, 1969). Como os diplomas expedidos eram negados pelo governo federal quando os bacharéis de Porto Alegre requeriam a sua validação, pois o curso não tinha fiscalização e não era equiparado aos congêneres mantidos pela União, alguns estudantes se organizaram e fundaram um Centro dos Acadêmicos de Direito a fim de pressionarem a direção e os professores no sentido de que a Faculdade se adequasse à lei de 1915.

Inicialmente resolveram fazer uma "visita" ao diretor André da Rocha para tentar convencê-lo a convocar a Congregação para que o assunto fosse discutido. Dias de Azevedo foi um dos encarregados pelos colegas de participar da entrevista com o diretor que, segundo ele, colocou-se contra o pedido de convocação. Teria dito que a "lei Maximiliano" seria "em breve [...] derrubada pelo Congresso Nacional, pois tal era o empenho do dr. Borges de Medeiros". André da Rocha teria ainda ponderado que a Faculdade precisava realizar alguns gastos com obras necessárias à conservação do seu prédio, com o que não dispunha de recursos para a remuneração de um fiscal federal caso fosse lograda a equiparação. Após a negativa do diretor, os alunos passaram a procurar os professores um a um a fim de obter deles o pedido de convocação da Congregação. Obtiveram sucesso. Então, André da Rocha teria aceitado as ponderações em favor do pedido de equiparação, providenciando as adequações necessárias (AZEVEDO, 1969). Com isso, aceitava-se a fiscalização federal, admitia-se o ingresso por vestibular e a cadeira de Teoria Geral do Direito seria substituída pela de Filosofia do Direito. Porém, a questão ainda se arrastaria até 1920 , quando, após o primeiro pedido de equiparação ter sido negado pelo governo federal, finalmente a Faculdade readquiriria tal estatuto (TILL, 2000: 248-51).

A questão da equiparação é emblemática tanto da estreita relação entre a Faculdade e o governo do estado, quanto 
também de sua possível autonomia. Não parece equivocado afirmar que, quanto à reforma Carlos Maximiliano, "as mudanças na legislação escolar vieram com as mudanças políticas" (CUNHA, 1980: 167). O fim do governo Hermes abalou a capacidade de influência do PRR na política nacional, o que se podia mesmo aquilatar pela própria perda da anterior ascendência de Pinheiro Machado no Congresso à mesma época (ver LOVE, 1975: 177 e seguintes). Isto abriu caminho para uma reforma que punha estreitos limites à liberalização do ensino em termos de sua desoficialização, desregulamentação e ampliação do campo de atuação das iniciativas particulares.

Além disto, a própria nomeação de Carlos Maximiliano como ministro da Justiça e Interior parece ter sido uma acomodação que visava evitar maiores reações do governo do Rio Grande do Sul quanto às reformas que vinham de encontro ao que há muito pregavam o programa do PRR e a Constituição estadual de 1891. Porém, se num primeiro momento Borges de Medeiros ficou contrário ao decreto de 1915, parece que sua rejeição não se tornou uma questão fechada ou um ponto com o qual não fosse possível transigir. $O$ ministro rio-grandense nomeado contra a vontade de Pinheiro Machado seria depois reconduzido à Câmara federal (1918) pelo próprio PRR, o que indica que então Borges não se incompatibilizara totalmente com Maximiliano, o que ocorreria somente em 1923, quando este último se colocou contra a reeleição de Borges para a presidência do estado (ver ABREU, 2001: 3647). Por outro lado, na Exposição de Motivos de seu decreto acima citada, o ministro se colocava como favorável em princípio à desoficialização do ensino. Ele apenas não a via como possível no Brasil daquele momento e, além disso, cita explicitamente o caso do ensino superior no Rio Grande do Sul de uma forma elogiosa, pois lá o governo "auxilia os cursos superiores: não os sustenta nem se responsabiliza pelas suas dívidas. Não nomeia professores; não lhes garante ordenado, vitaliciedade e jubilação. Ou as Congregações economizam ou desaparecem" (MAXIMILIANO, 1915). 
A razão evocada por André da Rocha para que a Faculdade não requeresse a equiparação, julgar ele que o decreto seria derrubado no Congresso já que Borges estava atuando neste sentido, termina por ser vencida frente à quase unanimidade do apoio estudantil à tese contrária. O pragmatismo vence as possíveis resistências do presidente do estado e do diretor da Faculdade. No relato de Armando Dias de Azevedo, a questão parece ter sido encaminhada pelos alunos de forma a que não fosse político-partidarizada. Os líderes estudantis buscaram apresentá-la como uma dificuldade prática para os diplomados pela Faculdade, pois ficavam restritas as suas possibilidades de exercício profissional fora do Rio Grande do Sul, além de estarem impedidos de ocupar cargos públicos federais para os quais se exigissem diplomas validados pelos órgãos competentes mesmo nesse estado. Por outro lado, a demora de quase três anos para que se conseguisse o reconhecimento pode também indicar que deve ter havido falta de apoio das bancadas do PRR no Rio de Janeiro à demanda encaminhada, o que apontaria para que Borges não estava se empenhado muito na questão, ou mesmo que o governo federal estava efetivamente interessado em obstaculizar ao máximo as equiparações.

Ainda digno de nota quanto à reforma Carlos Maximiliano e que teria repercussões posteriores para a Faculdade de Direito é que ela explicitamente previa a instalação de uma universidade no Brasil. Esta seria localizada na capital federal e se comporia pela "reunião" da Escola Politécnica e de Medicina do Rio de Janeiro (estas oficiais) e por uma das faculdades de direito (estas particulares) da mesma cidade (MAXIMILIANO, 1915). A Universidade do Rio de Janeiro acabou por ser fundada em 1920, justamente a partir da reunião das escolas referidas, por um decreto federal. Segundo algumas fontes, isso se deu devido à visita do rei Alberto, da Bélgica, ao Brasil, para o qual alguns criam conveniente condecorar com um título de doutor honoris causa, sendo para tal necessária uma Universidade para perpetrar tal ato o que foi legalmente providenciado (CUNHA, 1980: 190). 
QUANDO O PRIVADO TEM INTERESSE PÚBLICO: A FUNDAÇÃO...

Em 1925, nova reforma, conhecida como Rocha Vaz, limitaria ainda mais o campo de autonomia relativa das instituições de ensino em geral. Posto em vigor no governo Artur Bernardes e em meio aos distúrbios que se espraiavam pelo país, sendo que no Rio Grande do Sul se destacaram a chamada revolução de 1923 e os levantes tenentistas de 1924, 1925 e 1926, o decreto 16.728-A, embora previsse subsídios federais às associações discentes com fins "científicos, literários ou de assistência escolar", criava mecanismos de repressão a manifestações político-partidárias por parte de estudantes e criava ainda a disciplina de Moral e Cívica nas escolas primárias e secundárias explicitamente para tomar "medidas defensivas da sociedade enquanto é tempo". Centralizava ainda mais as decisões sobre o ensino no país em torno do Departamento Nacional de Ensino, ligado diretamente ao Ministério da Justiça e Negócios Interiores. A reforma Rocha Vaz previa ainda a criação de outras universidades no Brasil, as quais deveriam se localizar nos estados de São Paulo, Pernambuco, Bahia, Minas Gerais e Rio Grande do Sul (ver CUNHA, 1980: 173-6 e VENÂNCIO FILHO, 1982: 216-7).

$\mathrm{Na}$ Faculdade de Direito de Porto Alegre, logo no ano seguinte, a Congregação procurou ajustar-se às reformas. $O$ corpo docente foi reorganizado, bem como a seriação das disciplinas e o currículo foram ajustados (SANTOS, 2000: 122-3). Nesta conjuntura Borges de Medeiros não estava mais em posição de enfrentar o governo federal em nome de um suposto purismo ideológico ou da afirmação da autonomia estadual. A década de 1920, com efeito, se iniciou com nova perda conjuntural de influência do PRR e de seu líder na política nacional, dado que o apoio de Borges à Reação Republicana e à derrotada candidatura Nilo Peçanha à presidência se mostrou pouco produtivo. Isto abriu a possibilidade de que as oposições no Rio Grande do Sul ao governo do PRR se unissem e lançassem a candidatura Assis Brasil à presidência do estado e, tendo perdido o pleito, se engajassem na revolta armada de 1923 esperando uma intervenção federal que derrubasse ou ao menos desestabilizasse a hegemonia do PRR. Borges de Medeiros 
logrou evitar a intervenção, embora tivesse de fazer concessões aos adversários. "Artur Bernardes foi o vencedor de fato de 1923", pois "tinha enfraquecido Borges em seu próprio reduto", principalmente por tê-lo feito aceitar o acordo de Pedras Altas que o obrigou a não concorrer a um novo mandato à presidência do estado (LOVE, 1975: 224). Sem maiores pressões vindas da política partidária, a Congregação da Faculdade opta por adaptar-se imediatamente às leis federais.

Depois de 1930 e até 1937, outras normas federais teriam forte repercussão no ensino em geral e para a Faculdade de Direito de Porto Alegre em especial. Trata-se do conjunto de decretos de 1931 que compuseram as chamadas reformas Francisco Campos, então ministro da Educação e Saúde Pública do governo provisório. Embora genericamente se concorde que "a revolução [...] não tinha um programa para a educação", o ministro encarregado de implementá-las fora responsável por reformas de ensino em seu estado natal, Minas Gerais, na década de 1920 (FÁVERO, 1977: 33).

Não é objetivo deste artigo e nem é possível nele discutir, pois seria para isto necessário um desvio muito grande do tema, as correntes reformistas da educação que, a partir do final da I Guerra Mundial, apareceram no Brasil (quanto ao ensino superior, ver CUNHA, 1980: 204-95 e, para o ensino em geral, ver NAGLE, 1976). Basta salientar queembora se concorde que não havia um projeto prévio bem definido para a área educacional entre os membros da Aliança Liberal, como já frisado, o assunto já vinha sendo discutido amplamente no Brasil. As reformas de ensino de Francisco Campos em Minas Gerais não foram as únicas, tendo ocorrido outras na Bahia (1924-1927) e no Distrito Federal (1926-1930), nas quais se destacaram aqueles que passavam a ser conhecidos como os especialistas em educação no país, dos primeiros nesta área, tais como Anísio Teixeira e Fernando de Azevedo, respectivamente (ver BOMENY, 2001). No mesmo período, mais especificamente em 1924, era fundada a Associação Brasileira de Educação ( $\mathrm{ABE}$ ), que passou a congregar diversos interessados na questão. A partir de 1926 Fernando de Azevedo coordena um "inquérito" sobre educação 
junto com o jornal O Estado de São Paulo e, em 1927, quando das comemorações do centenário da criação dos cursos jurídicos no Brasil, um Congresso de Ensino Superior fez parte das festividades realizadas na Faculdade de Direito da Universidade do Rio de Janeiro, sendo que as manifestações e discussões foram publicadas em um livro (VÁRIOS, 1929). Dentre estes "pensadores" e "reformadores" da educação e a partir da própria ABE duas correntes básicas podem ser distinguidas: a "liberal" e a "autoritária", segundo a nomenclatura de Cunha (1980: 205). A primeira, influenciada pelas experiências educacionais norteamericanas, era representada por Teixeira e Azevedo e a segunda, que recebia forte influência do fascismo europeu, por Campos.

Havia ainda no país um outro movimento organizado que se interessava em intervir nas políticas públicas para a área educacional. Trata-se do que se poderia genericamente denominar de "movimento católico", que tinha como base nacional o Centro Dom Vital. Alguns de seus membros atuavam diretamente dentro da própria $\mathrm{ABE}$. Estes defendiam maior ingerência da Igreja Católica no ensino do país, não só no que diz respeito ao apoio estatal para as suas escolas confessionais, como também pregavam a introdução do ensino religioso nas escolas públicas. Este movimento, anticomunista e antiliberal, teria mesmo contribuído para o fortalecimento das "correntes direitistas" dentro do governo que se organizou a partir de 1930 (CUNHA, 1980: 222-4).

Ou seja, embora as propostas da Aliança Liberal e do movimento revolucionário de 1930 não contemplassem especificamente a questão educacional, havia no Brasil diversos agentes cujas atividades práticas e intelectuais já se voltavam para o problema. Francisco Campos é recrutado para o Ministério da Educação e Saúde e Fernando Azevedo e Anísio Teixeira, este até 1935, colaboraram de forma mais ou menos direta com as reformas que se implementariam no ensino do país no pós-1930.

Quanto ao ensino superior, os decretos assinados por Francisco Campos explicitamente objetivavam "equiparar 
tecnicamente as elites profissionais do país e proporcionar ambiente propício às vocações especulativas e desinteressadas, cujo destino, imprescindível à formação da cultura nacional, é o da investigação e da ciência pura", ao mesmo tempo em que se propunham a "transcender" o "propósito do ensino", especificamente, tendo em vista uma ação "educativa" no "meio social" (apud, FÁVERO, 1977: 33-6). As reformas no âmbito do ensino superior consubstanciam-se no Estatuto das Universidades Brasileiras de 1931 que, enfim, terminava por reforçar "um tipo de educação humanista e elitizante" (FÁVERO, 1977: 36).

Nestes marcos regulatórios e linhas gerais de concepção sobre a organização do ensino superior no Brasil é que se inaugurou o processo de formação da Universidade de Porto Alegre (UPA), à qual se juntaria a Faculdade Livre de Direito. No Rio Grande do Sul seguiu-se a prática corrente no país de se instituir uma universidade a partir da aglutinação de escolas antes dispersas. No caso, a Faculdade de Direito (com o curso de comércio anexo), a Escola de Medicina (com os cursos anexos de odontologia e farmácia), a Universidade Técnica, então dissolvida (com os cursos de engenharia, agronomia, veterinária, química industrial e mais o Instituto Astronômico), e o Instituto de Belas Artes, segundo o decreto estadual de 28 de novembro de 1934, passariam a compor a UPA (GOVERNO do estado do Rio Grande do Sul, 1938: 202-27). O mesmo decreto de fundação da UPA previa ainda a criação de uma Faculdade de Educação, Ciências e Letras de acordo com os diplomas legais federais de Francisco Campos. A UPA, porém, somente teria a sua situação regularizada em 1936, depois de contornadas dificuldades jurídicas para a incorporação na Universidade da Escola de Medicina e de certos institutos da Universidade Técnica. A Escola de Medicina fora federalizada em 1931 e sua integração à Universidade estadual precisou de negociações com o governo federal e seus servidores. Já a Universidade Técnica, nova nomenclatura da antiga Escola de Engenharia, possuía uma situação especial com respeito ao reconhecimento de seus diplomas que seus membros relutaram em modificar. A 
QUANDO O PRIVADO TEM INTERESSE PÚBLICO: A FUNDAÇÃO...

aprovação dos estatutos da Universidade se deu apenas em 1940, quando se logrou obter a condição de equiparada às universidades federais. No entanto, foi somente em 1942 que se instalou a Faculdade de Educação com a denominação de Faculdade de Filosofia (ver SOARES; SILVA, 1992: 44 e seguintes).

Estudantes e professores da Faculdade de Direito tiveram importante participação neste processo de estruturação da UPA. $\mathrm{O}$ primeiro reitor designado pelo interventor federal e depois governador eleito do estado, José Antônio Flores da Cunha, foi o desembargador André da Rocha, ex-diretor da Faculdade de Direito, que permaneceria no cargo até 1937, quando foi destituído pelo interventor do Estado Novo general Dautro Filho. Por outro lado, nas dependências desta escola passaram a funcionar a reitoria e os demais serviços da administração central da Universidade.

A incorporação à nova instituição levou a que o estatuto jurídico da Faculdade de Direito fosse modificado. De instituto privado passou a ser público estadual. O patrimônio foi incorporado pela Universidade e seus professores se tornaram funcionários públicos. O diretor passou a ser indicado pelo chefe do governo estadual a partir de lista tríplice elaborada pela Congregação dentre os professores catedráticos. A administração passou a ser constituída pelo diretor, um Conselho Técnico Administrativo (CTA) e a Congregação. O Conselho, de acordo com as leis federais e os estatutos da UPA, se tornaria o órgão colegiado mais importante da administração escolar, pois organizava, disciplinava e fiscalizava desde questões didático-pedagógicas até concursos de admissão docente e discente. Seus membros eram escolhidos diretamente pelo chefe do governo estadual dentre os professores catedráticos apontados pela Congregação na ordem de um número duplo daquele das vagas disponíveis. Seguindo os estatutos das universidades mantidas pela União e o que dispunha a legislação federal, os professores catedráticos seriam escolhidos mediante concurso público, sendo que se previa ainda o regime docente de professor contratado, sendo os 
últimos escolhidos pelo CTA por tempo limitado e com a concordância do Conselho Universitário.

Estas condições institucionais e administrativas pouco se alterariam ao longo do tempo até 1950, quando a Universidade, que mudara de nome em 1947 para Universidade do Rio Grande do Sul (URGS), seria federalizada, dando origem a atual Universidade Federal do Rio Grande do Sul (UFRGS).

\section{Patrimônio e Condições Materiais}

Quanto às condições materiais e patrimoniais da Faculdade de Direito, é importante ressaltar alguns pontos, pois neste sentido concorreram em muito o governo do estado e a intendência municipal de Porto Alegre.

A lei de 1895 previa a necessidade de um patrimônio de 50:000\$000 para que uma faculdade livre pudesse requerer a equiparação às congêneres federais. Desde este momento teria o governo do estado servido de avalista e garantidor de tal patrimônio à Faculdade de Direito e desde então contribuiria mais ou menos regularmente com recursos para o aumento do mesmo. Ao longo do tempo, pois, até a estadualização, embora a escola contasse com recursos próprios que auferia nas cobranças de taxas e matrículas dos alunos, sempre dependeu de outras fontes de sustento, tais como os poderes públicos e o concurso esporádico de doações de particulares. Os próprios professores "serviam gratuitamente desde o ano de 1906. Em Congregação de dezembro de 1905 foi fixada pequena remuneração para os serviços de aulas e de exames, a contar de janeiro de 1906" (VÁRIOS, 1927: 108).

O aporte de recursos por meio de doações foi especialmente importante para a constituição do acervo da biblioteca da instituição. Esta foi inaugurada em 1906 com 774 volumes e ao longo do tempo contou com o auxílio de alguns professores e seus herdeiros que fizeram diversas doações de suas bibliotecas particulares para a da Faculdade. Além disto, 
os vencimentos, de 3:600\$000 anuais, como fiscal federal da instituição do desembargador James de Oliveira Franco e Souza foram por ele destinados em 1906 e 1907 em seu benefício, sendo que de 1908 em diante ele canalizou os recursos citados para as obras de construção do prédio-sede da escola (ver TILL, 2000: 477-83).

A construção da sede própria (dados a este respeito extraído de TILL, 2000: 190-223), por seu turno, foi um momento significativo do concurso dos poderes públicos para o aumento patrimonial da instituição. Inicialmente ela funcionava em salas cedidas pelo governo do estado no edifício da antiga Escola Normal. Em 1907 a Congregação optou por iniciar tratativas para a compra de um terreno para a construção do prédio próprio. $O$ desembargador e diretor André da Rocha e o professor e secretário da Faculdade Leonardo Macedônia Franco e Souza, filho do desembargador James de Oliveira Franco e Souza, que era também consultor jurídico do município de Porto Alegre, conseguiram junto ao governador Borges de Medeiros e ao intendente municipal José Montaury a doação do terreno. Neste se localizava um parque de diversões cujo concessionário teve de ser indenizado pela Faculdade com 8:000\$000, que assim ficou com a posse do local que foi acrescido em 1909 de uma área contígua por meio de outra doação do município. No período os professores abriram mão de $25 \%$ de seus rendimentos auferidos nas atividades na escola para a construção da sede (VÁRIOS, 1927: 111).

A obra foi orçada inicialmente em 200:000 $\$ 000$, tendo consumido 312:530\$190 ao longo dos dois anos que levou para ser terminada. Para pagar este valor, o governo do estado contribuiu com algo em torno de 140:000\$000 e a intendência de Porto Alegre com outros 20:000\$000 (VÁRIOS, 1927: 112-5) até 1910, ano da inauguração, sendo que a Congregação aprovou que tanto o governo estadual quanto o municipal poderiam contar a partir de então com duas vagas na Faculdade para os estudos de alunos que indicassem, os quais ficariam isentos de pagar taxas e matrículas. Além disso, foram dedicadas várias homenagens ao intendente e a Borges de Medeiros, como a 
placa, instalada em 1925, que se encontra atualmente no átrio do prédio e onde se pode ler: "aos eméritos drs. A. A. Borges de Medeiros e Montaury de A. Leitão - gratidão".

Por outro lado, a Congregação da Faculdade também autorizou o diretor a recorrer a empréstimos bancários para que fossem completados os recursos necessários para a conclusão das obras. Foi ainda lançada pelos alunos uma campanha para angariar doações que contou com o apoio de órgãos de imprensa. Eles realizaram uma "quermesse", que teve como "patronesse" a esposa de Borges de Medeiros, além de outras "senhoras" da "alta sociedade" porto-alegrense. A festa teria arrecadado 8:000\$000 com a venda de objetos doados por simpatizantes de todo o estado (TILL, 2000: 205-10).

A inauguração do prédio foi noticiada no Correio do Povo de 19 de agosto de 1910. Deu-se com um baile organizado pelos formandos nas dependências da nova sede. Estavam "presentes centenas de senhoras, senhoritas e cavalheiros, inclusive o corpo docente da Faculdade de Direito, [...] e altas autoridades civis e militares. [...] Em frente ao edifício da Faculdade, estacionaram quase todos os carros particulares aqui existentes" (apud, TILL, 2000: 221-2), o que demonstra a importância social que o evento teve para as elites locais.

Porém, os auxílios governamentais não se limitaram a estes do período da construção. Em 1910 o patrimônio da escola se constituía do prédio novo no valor de $312: 530 \$ 190$, do terreno com área de $7.039 \mathrm{~m}^{2}$, da biblioteca com 2.200 volumes e de móveis e utensílios. Possuía uma dívida bancária de 100:500\$000 ainda relativa aos custos das obras da sede. Em 1911 o governo do estado aportou 50:000\$000 e o municipal 10:000\$000, sendo que a dívida diminui para 67:000\$000. No ano seguinte o governo federal contribui com 20:000\$000, o estadual com 50:000\$000 e o municipal com 15:000\$000, com o que as dívidas com as obras do prédio foram quitadas neste mesmo ano. Em 1915 o município aportaria mais 5:000\$000 (ver VÁRIOS, 1927: 116-8 e TILL, 2000: 205-10).

Computados os totais dos aportes de recursos públicos até a quitação dos encargos com a construção do prédio, tem-se que 
estes somam 20:000\$000 do governo federal, 240:000\$000 do governo do estado e mais 45:000\$000 do município. Ou seja, dos 312:530\$190 aplicados na obra, 305:000\$000 foram pagos com recursos públicos, sendo que o governo do estado contribuiu com a maior parte. Isto sem contar os valores dos terrenos doados. Ou seja, a instituição privada Faculdade Livre de Direito de Porto Alegre constituiu e aumentou seu patrimônio fundamentalmente devido aos recursos repassados pelas três instâncias administrativas e governamentais públicas. Para se ter uma idéia do volume dos recursos aplicados na construção da sede da Faculdade, o orçamento total para a "instrução primária" do estado do Rio Grande do Sul para todo o ano de 1908, a maior rubrica do "nosso orçamento" e a maior relação recursos/população dentre os estados do Brasil, foi de 2.261:357\$000, segundo o Relatório apresentado ao presidente do estado Carlos Barbosa Gonçalves por Protásio Antônio Alves, Secretário dos Negócios do Interior e Exterior, em 8 de setembro de 1910. (ALVES, 1910: V e 445). Ou seja, o prédio teria custado ao todo aproximadamente $1 / 7$ do valor deste orçamento.

Mas os aportes de recursos públicos não cessaram depois de pagos os encargos com a construção do prédio. Num relatório de 1916 à Congregação, André da Rocha apresenta um balanço das receitas e despesas da escola. Os ingressos foram de $77: 941 \$ 200$ e os gastos $56: 195 \$ 720$, o que resultou em saldo positivo de $21: 745 \$ 480$. No mesmo relatório é referido que o governo estadual não teria aportado 20:000\$000 que seriam destinados ao "conserto do telhado", embora conste o mesmo valor como concessão para o ano de 1917 e mais 6:600\$000 da intendência de Porto Alegre (ROCHA, 1917: 10).

Estes dados evidenciam que a manutenção da escola era de interesse dos governos do PRR e de seu líder Borges de Medeiros. Ainda mais que os aportes mais significativos se iniciam justamente em 1907, ano em que o PRR sofreu as dissidências internas que redundaram na candidatura de Fernando Abott à presidência do estado em oposição ao candidato de Borges de Medeiros, Carlos Barbosa. A disputa eleitoral afetou sensivelmente a escola de direito, pois alguns de 
seus professores e muitos dos alunos se colocaram em favor da candidatura Abott, enquanto que outros tantos optaram pela de Carlos Barbosa. Por outro lado, a época da conclusão das obras coincide com as eleições para a presidência da República de Hermes da Fonseca, disputadas contra Rui Barbosa que contava com vários simpatizantes no Rio Grande do Sul, notadamente o professor da Faculdade Arthur Pinto da Rocha. Com Hermes já presidente, em 1912, aparecem os recursos federais. É possível que não tenha havido uma relação direta entre os aportes de recursos e uma tentativa de aplacar os ânimos estudantis e de alguns docentes contra os governos do PRR e de Hermes por ele apoiado no plano federal, mas isto pode ter contribuído para tal, mostrando igualmente a importância que davam à existência da instituição as principais lideranças do partido.

Com a estadualização em 1934, porém, o patrimônio da Faculdade de Direito seria incorporado ao da UPA, passando, então, ao direto controle estatal.

\section{Considerações finais}

Pelo exposto e analisado ao longo deste artigo, ficam evidentes as ligações institucionais e de certos agentes-chave da Faculdade com o governo do estado do Rio Grande do Sul, com a intendência municipal de Porto Alegre e, principalmente, com o PRR e Borges de Medeiros. Não parece exagerado afirmar que sem o apoio destas administrações públicas, notadamente o financeiro e patrimonial, teria sido inviável a criação e a manutenção da instituição. A existência da escola, inicialmente uma sociedade de direito privado, pois, esteve sempre atrelada ao apoio de lideranças político-partidárias da facção política dominante no estado. Mas estas relações assumiam também um outro caráter, aquele que atrelava a líderes políticos em posições importantes os agentes da instituição, seus professores e alunos, muitos dos quais também eram profundamente engajados na esfera das disputas do jogo político. 
Portanto, a despeito e ao contrário do que alguns trabalhos apontam a respeito da Faculdade e sua suposta independência e autonomia frente ao governo do estado e ao partido político dominante, o PRR, o que se pode constatar é uma estreita relação. Se esta não se dava pela via do controle governamental direto, dava-se por meio de uma série de mecanismos que incluíam diretores sintonizados com as lideranças políticas, uma relação estreita entre o regramento jurídico e a tomada de posições dos agentes da instituição e do governo do estado e uma evolução patrimonial totalmente dependente de recursos públicos.

\section{Referências Bibliográficas}

ABREU, Alzira Alves de et al. (coord.). Dicionário histórico-biográfico brasileiro pós-30. Rio de Janeiro, CPDOC/FGV, 2001.

ALVES, Protásio Antônio. Relatório apresentado ao sr. dr. Carlos Barbosa Gonçalves - Presidente do Estado do Rio Grande do Sul - pelo dr. Protásio Antônio Alves - Secretário dos Negócios do Interior e Exterior - em 8 de setembro de 1910. Porto Alegre, Typ. da Livraria Universal, 1910.

AZEVEDO, Armando Dias de. Vitória duma reivindicação estudantil em 1917. Correio do Povo. Porto Alegre, 10 de outubro de 1969.

BASTOS, Aurélio Wander. O ensino jurídico no Brasil. Rio de Janeiro, Lumen Júris, 2000.

BOMENY, Helena. Os intelectuais da educação. Rio de Janeiro, Jorge Zahar, 2001.

BRASIL. Senado federal. Secretaria de Informações e Documentação. Dados biográficos dos senadores do Rio Grande do Sul: 1826-1999. Brasília, Senado Federal, 1999.

CAGGIANI, Ivo. Flores da Cunha - biografia. Porto Alegre, Martins Livreiro, 1996.

CONSTITUIÇÃO Política do Estado do Rio Grande do Sul. In: CARNEIRO, Paulo (org.). Idéias políticas de Júlio de Castilhos. Brasília/Rio de Janeiro, Senado Federal/Casa de Rui Barbosa, 1982, p. 
446-461.

CORRÊA, Rivadávia. Decreto n. 8659 de 5 de abril de 1911. In: MOACYR, Primitivo. A instrução e a República. Rio de Janeiro, Imprensa Nacional, vol. 4, 1942.

CUNHA, Luiz Antônio. A universidade temporã: o ensino superior da colônia à era Vargas. Rio de Janeiro, Civilização Brasileira, 1980.

FÁVERO, Maria de Lourdes de Albuquerque. A universidade brasileira: em busca de sua identidade. Petrópolis, Vozes, 1977.

FONTOURA, João Neves da. Memórias: Borges de Medeiros e seu tempo. Porto Alegre, Globo, 1969, p. 90.

FRANCO, James Macedônia. Faculdade de direito de Porto Alegre: setenta e um anos de serviços ao RGS. Correio do Povo. Porto Alegre, 14 de fevereiro de 1971.

FRANCO, Sérgio da Costa. Júlio de Castilhos e sua época. Porto Alegre, UFRGS, 1988.

GOVERNO do estado do Rio Grande do Sul. Leis, decretos e atos do governo do estado do Rio Grande do Sul - 1934. Porto Alegre, Imprensa Oficial, 1938.

GOVERNO do estado do Rio Grande do Sul. Leis, decretos e atos do governo do estado do Rio Grande do Sul - 1895. Porto Alegre, Oficinas gráficas de A Federação, 1920.

GRIJÓ, Luiz Alberto. Ensino jurídico e política partidária no Brasil: a Faculdade de Direito de Porto Alegre (1900-1937). Niterói, Tese de Doutorado em História Social/PPGH/UFF, 2005.

LOVE, Joseph. O regionalismo gaúcho e as origens da revolução de 1930. São Paulo, Perspectiva, 1975.

MARTINS, Ari. Escritores do Rio Grande do Sul. Porto Alegre, Editora da UFRGS/IEL, 1978.

MAXIMILIANO, Carlos. Decreto n. 11530 de 18 de março de 1915. In.: MOACYR, Primitivo. A instrução e a República. Rio de Janeiro, Imprensa Nacional, vol. 4, 1942.

MENDES, Maralúcia Rodrigues. Entre o "saber" e o "poder": os políticos profissionais do governo castilhista (1891-1900). Porto Alegre, Dissertação de Mestrado em Ciência Política/PPGCP/UFRGS, 1999.

MOACYR, Primitivo. A instrução e a República. Rio de Janeiro, Imprensa Nacional, vol. 4, 1942.

NAGLE, Jorge. Educação e sociedade na Primeira República. São Paulo/Rio de Janeiro, E.P.U./Fundação Nacional de Material Escolar, 1976.

RAMOS, Oscar. A Federação, 10 de fevereiro de 1904. 
ROCHA a MEDEIROS - Carta de Manoel André da Rocha a Borges de Medeiros, 01 de janeiro de 1905 (ABM-IHGRS, doc. 4715).

ROCHA a MEDEIROS - Carta de Manoel André da Rocha a Borges de Medeiros, 05 de janeiro de 1913 (ABM-IHGRS, doc. 5187).

ROCHA, Manoel André da. Relatório apresentado à Congregação dos lentes em sessão de 31 de dezembro de 1916. Porto Alegre, Livraria Americana/Cunha, Rentzsch \& Cia., 1917.

SANTOS, João Pedro dos. A Faculdade de Direito de Porto Alegre: subsídios para sua história. Porto Alegre, Síntese, 2000.

SOARES, Mozart Pereira; SILVA, Pery Pinto Diniz da. Memória da Universidade Federal do Rio Grande do Sul (1934-1964). Porto Alegre, UFRGS, 1992.

TILL, Rodrigues. História da Faculdade de Direito de Porto Alegre (19002000). Porto Alegre, Martins Livreiro, 2000.

VÁRIOS. Livro do centenário dos cursos jurídicos (1827-1927). Livro II: Trabalhos do Congresso de Ensino Superior. Rio de Janeiro, Imprensa Nacional, 1929.

VÁRIOS. Livro do centenário dos cursos jurídicos no Brasil. Porto Alegre, Livraria Americana/J. O. Rentzsch \& Cia., 1927.

VENÂNCIO FILHO, Alberto. Das arcadas ao bacharelismo (150 anos de ensino jurídico no Brasil). São Paulo, Perspectiva, 1982.

GRIJÓ, Luiz Alberto. When the Private has a Public interest: the foundation and the institutional trajectory of the Faculdade de Direito de Porto Alegre (1900-1937). História, v.28, n.2, p.303-338, 2009.

Abstract: The present article approaches the institutional trajectory of the Faculdade de Direito de Porto Alegre (Porto Alegre Law School), since its foundation in 1900 up to 1937. First are analyzed its directors, then the relationships between the School and federal laws and, finally, its patrimonial evolution. Unlike some works sustain, it can be affirmed that without the support of public administrations, especially by financial and patrimonial resources, it would have been impossible the creation and the maintenance of the institution. The existence of the school, initially a private one, therefore, was always attached 
to the support of political leaderships from the hegemonic political faction in the Brazilian's state of Rio Grande do Sul.

Keywords: Juridical education in Rio Grande do Sul; Juridical education in Brazil; Porto Alegre Law School; Law Schools in Brazil; Juridical and political formation.

\section{NOTAS}

${ }^{1}$ Este artigo é baseado em parte de minha tese de doutorado. Ver GRIJÓ, 2005.

Artigo recebido em 08/2009. Aprovado em 10/2009. 